\title{
Erratum to: Ammonia Toxicity to the Freshwater Planarian Polycelis felina: Contrasting Effects of Continuous Versus Discontinuous Exposures
}

\author{
Álvaro Alonso ${ }^{1}$ · Julio A. Camargo ${ }^{1}$
}

Published online: 25 June 2015

(c) Springer Science+Business Media New York 2015

Erratum to: Arch Environ Contam Toxicol (2015) 68:689-695

DOI 10.1007/s00244-015-0129-8

The original version of this article unfortunately contained a mistake. The Research Project number was incorrect in the Acknowledgments section. The correct Research Project number is CGL2011-28585. The authors apologize for this mistake and the inconvenience caused to the readers.

The online version of the original article can be found under doi: 10 . 1007/s00244-015-0129-8.

Álvaro Alonso

aafernandez1976@yahoo.es

1 Unidad Docente de Ecología, Departamento de Ciencias de la Vida, Facultad de Biología, Ciencias Ambientales y Química, Universidad de Alcalá, 28871 Alcalá de Henares, Madrid, Spain 